\title{
Modifying oxide nanomaterials' properties by hydrogenation
}

\author{
Xiaodong Yan, Department of Chemistry, University of Missouri-Kansas City, Kansas City, M0 64110, USA \\ Lihong Tian, Department of Chemistry, University of Missouri-Kansas City, Kansas City, M0 64110, USA; Hubei Collaborative Innovation Center for \\ Advanced Organochemical Materials, Ministry of Education Key Laboratory for the Synthesis and Applications of Organic Functional Molecules, Hubei \\ University, Wuhan 430062, China \\ Xinyu Tan, College of Materials and Chemical Engineering, Hubei Provincial Collaborative Innovation Center for New Energy Microgrid, China Three Gorges \\ University, Yichang 443002, China \\ Minjie Zhou, School of Chemistry and Chemical Engineering, Hunan Institute of Science and Technology, Yueyang 414000, China \\ Lei Liu, State Key Laboratory of Luminescence and Applications, Changchun Institute of Optics, Fine Mechanics and Physics, Chinese Academy of Sciences, \\ Changchun 130033, China
}

Xiaobo Chen, Department of Chemistry, University of Missouri-Kansas City, Kansas City, M0 64110, USA

Address all correspondence to Xiaobo Chen at chenxiaobo@umkc.edu

(Received 3 May 2016; accepted 22 August 2016)

\begin{abstract}
Nanomaterials have been intensively studied over the past decades with many advantages over traditional bulk materials in many applications. Nanomaterials' properties are largely governed by their chemical compositions, sizes, shapes, dimensions, morphologies and structures, which are primarily controlled with the chemical and/or physical fabrication methods and processes. This prospective will highlight recent progress on the modifications of oxide nanomaterials' properties by hydrogenation, namely heat treatment under hydrogen or hydrogen plasma environment, for various applications.
\end{abstract}

\section{Introduction}

It is well known that the performance of nanomaterials in various applications depends largely on their properties, which are controlled by their chemical compositions, physical sizes, dimensions, structures, and morphologies. ${ }^{[1-3]}$ The past decades have witnessed the blooming fruits of the efforts in the property manipulations with nanoscale size and morphology tuning. ${ }^{[1-3]}$ Representative examples are the large flexibilities of the optical absorption and emission properties of quantum dots or plasmonic particles by changing their sizes and morphologies, benefited from the changes of the electronic structure or plasmonic resonance upon those changes in their physical properties. ${ }^{[1-3]}$ Another example is the large variation of the chemical and catalytic activities with the change of the size of the nanomaterials, which reversely increases the specific surface area and the portion of atoms exposed on the surface with dangling bonds, along with the change of exposed surface facets. ${ }^{[1-3]}$ The findings in these two phenomena have opened new applications or enhanced performances of nanomaterials in catalysis, electronics, biosensing, imaging, etc. The recent discovery of black titanium dioxide $\left(\mathrm{TiO}_{2}\right)$ suggests that the optical, electronic, and catalytic activities of nanomaterials can be largely modified by treating them in hydrogen environment at elevated temperature, or namely by a hydrogenation process. ${ }^{[4]}$ For example, the color of $\mathrm{TiO}_{2}$ nanoparticles changes dramatically from white to black after hydrogenation, the electronic band structure is largely altered, and the photocatalytic activity is dramatically enhanced for both solar hydrogen generation from water and photocatalytic pollution removal. ${ }^{[4]}$ The report of those large changes in the properties of $\mathrm{TiO}_{2}$ nanoparticles has spurred a wide interests across various fields using hydrogenation as a new tool to modify the properties of various oxide nanomaterials for different applications as shown in Fig. $1 .^{[5-20]}$ The structural, chemical, electronic and optical properties of oxide nanomaterials can be largely modified by hydrogenation treatment. For example, after hydrogenation, crystalline/disordered core/shell nanoparticles can be created easily otherwise with much difficulty, long-wavelength absorption can be introduced, structural and chemical defects are introduced, and enhanced electrical conductivity can be obtained. Those property changes can lead to large performance improvements for their applications in photocatalysis, electrocatalysis, photoelectrocatalysis, rechargeable batteries, and supercapacitors, and trigger new applications such as photothermal image/therapy, field emission, ferromagnetism, and microwave absorption. Future studies may further reveal more interesting properties and applications of oxide nanomaterials after hydrogenation treatment. In this short perspective, we present some representative examples to demonstrate the progress in this area. We believe such a summary would provide some helpful information and inspire new thoughts and ideas to further advance the progress in related research areas. 


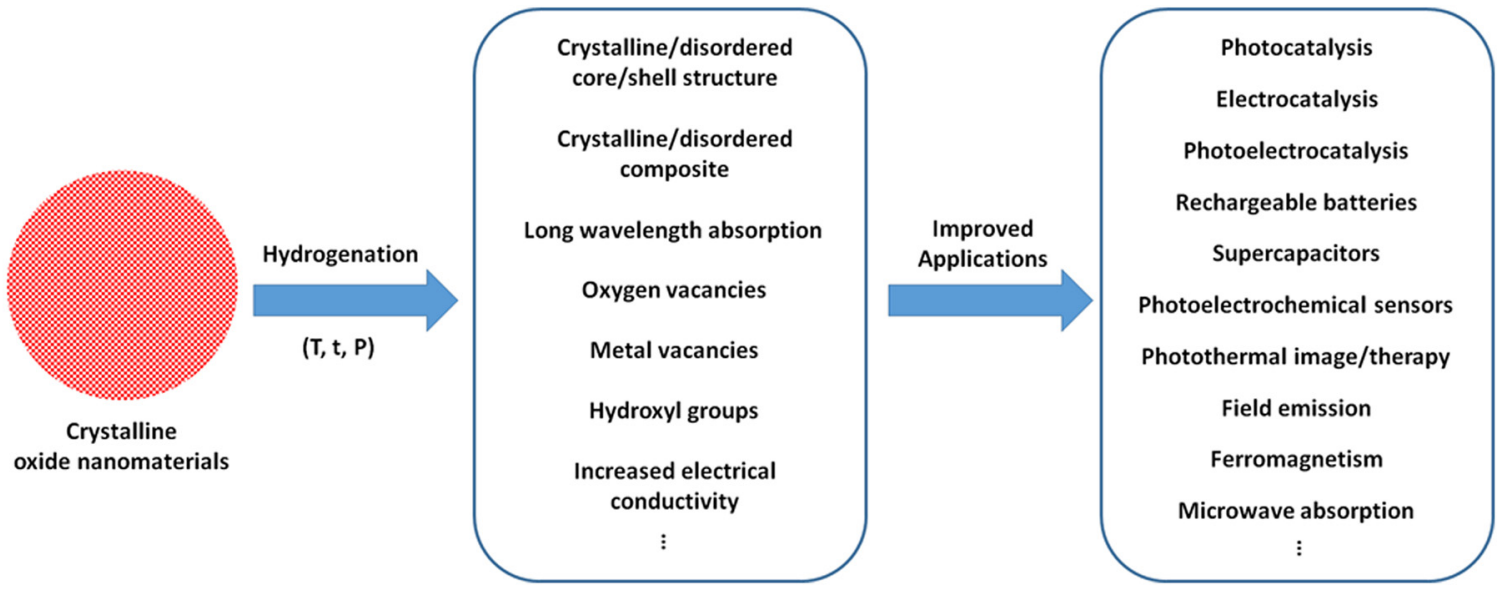

Figure 1. A brief summary of the characteristics of oxide nanomaterials after hydrogenation and the related applications.

\section{Hydrogenation process}

First, we want to define the term "hydrogenation" to remove some possible confusion. The hydrogenation process here refers to the treatment of materials under hydrogen-containing environment or hydrogen plasma for certain period of time at some temperatures. Hydrogenation - to treat with hydrogenis commonly employed in organic industries and laboratories to reduce or saturate organic compounds where hydrogenation typically constitutes the addition of pairs of hydrogen atoms to a molecule. In the hydrogenation process here, the nanomaterials may or may not be reduced, depending on the hydrogenation conditions. Possible results of hydrogenation of inorganic nanomaterials can produce the following typical scenarios, as shown in Fig. 2. (A), hydrogenation can only induce structural alteration, e.g. from crystalline phase to disordered phase, but without measurable chemical valence state changes, forming crystalline/disordered core/shell nanostructures. (B), hydrogenation induces partial chemical reduction to introduce lower valence state or oxygen vacancies. (C), hydrogenation causes deep chemical reduction to form completely reduced

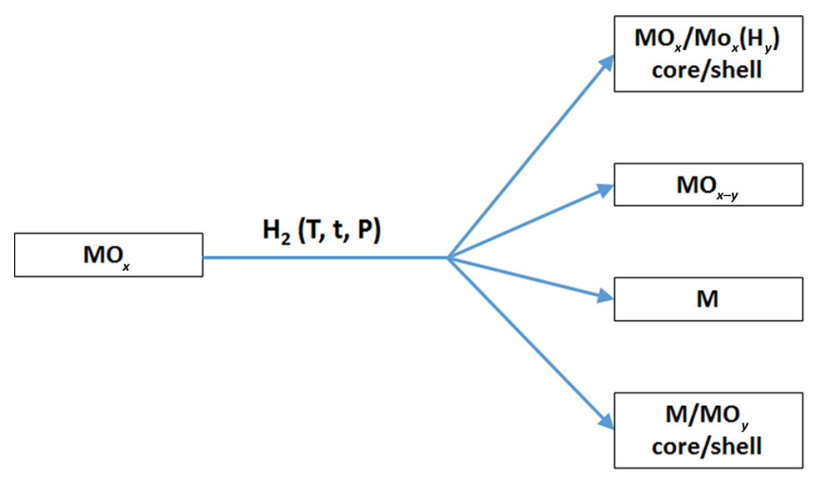

Figure 2. Illustration of some possible scenarios of the chemical composition changes for oxide materials after hydrogenation treatments. metallic phase. (D), hydrogenation makes complete chemical reduction to form metallic phase, but the followed exposure to air in ambient environment induces oxidation on the surface to form disordered layer, resulting crystalline/disordered metal/ oxide core/shell nanostructures. The formation of the above nanostructures depends on the nature of the nanomaterial and the hydrogenation conditions, such as the hydrogenation temperature, time, hydrogen pressure, and the composition of the atmosphere containing the hydrogen gas. Thus, the control of the hydrogenation process after common nanomaterials' synthesis or fabrication steps can further increase the choices of the nanomaterials' chemical compositions, structures and phases to induce desirable properties for various applications. In the following sections, we will present some representative examples to show how the hydrogenation can alter the structural, chemical, electronic and optical properties of some oxide nanomaterials along with their related performance in various applications.

\section{Hydrogenated $\mathrm{TiO}_{2}$ nanomaterials}

Hydrogenated $\mathrm{TiO}_{2}$ single crystals were reported in 1951 with long-wavelength absorption ${ }^{[5]}$ and in 1958 with increased electrical conductivity ${ }^{[6]}$ due to the existence of oxygen vacancies $^{[6,7]}$ or mostly Ti interstitial defects. ${ }^{[8,9]}$ Pale blue or dark blue $\mathrm{TiO}_{2}$ was obtained. ${ }^{[7]}$ While molecular hydrogen did not interact strongly with $\mathrm{TiO}_{2}$ surfaces, ${ }^{[10]}$ high doses of $\mathrm{H}_{2}$ induced additional emission peaks in the valence band region even at room temperature, ${ }^{[11]}$ and at room temperature atomic hydrogen stuck to $\mathrm{TiO}_{2}$ (110) surfaces. ${ }^{[12]}$ Hydrogenation on $\mathrm{TiO}_{2}$ surface in a $\mathrm{H}_{2}$ atmosphere of a very low pressure could induce chemical reduction, ${ }^{[1,14]}$ and increased the photoactivity. ${ }^{[15,16]}$ However, a large interest on the hydrogeantion of $\mathrm{TiO}_{2}$ nanomaterials did not appear until our report of the striking color change into black color and the related dramatic electronic and photocatalytic property changes. ${ }^{[17-25]}$ When anatase $\mathrm{TiO}_{2}$ nanocrystals go through hydrogenation under 

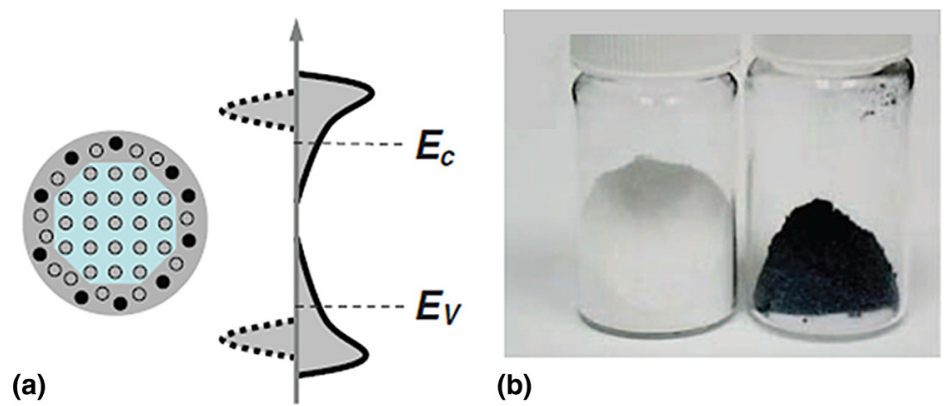

(b)
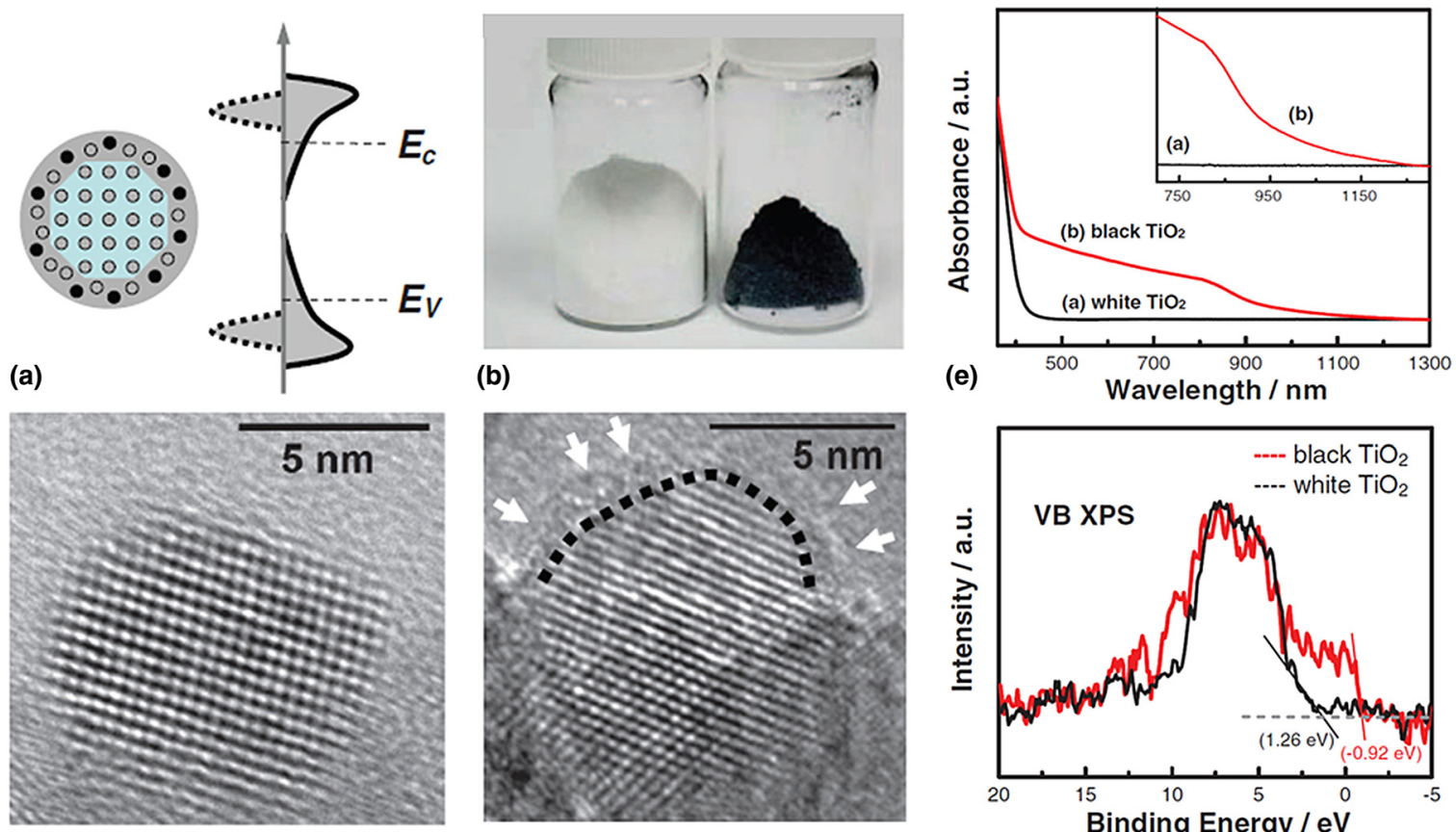

(d)

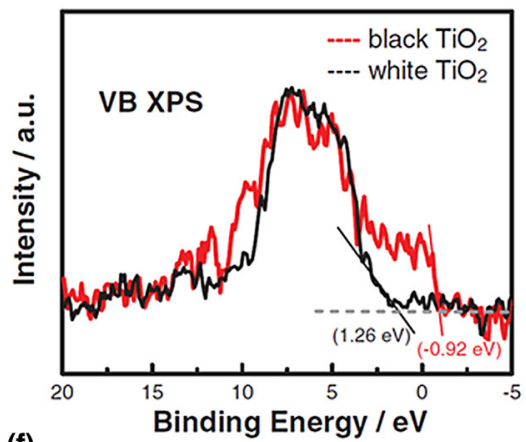

(f)

Figure 3. (a) A schematic illustration of the lattice and electronic structures of hydrogenated black $\mathrm{TiO}_{2}$, (b) Digital pictures of white and hydrogenated black $\mathrm{TiO}_{2}$, (c) HRTEM image of white $\mathrm{TiO}_{2}$, (d) HRTEM image of white $\mathrm{TiO}_{2}$, (e) UV-vis and (f) VB-XPS spectra of white and hydrogenated black $\mathrm{TiO}_{2}$. Reproduced with permission from Ref. 4, Copyright 2011 AAAS.

high-pressure $\mathrm{H}_{2}$ environment at $200{ }^{\circ} \mathrm{C}$ for a few days, a crystalline/disordered core/shell nanoparticle is formed without detectable species of reduced $\mathrm{Ti}^{3+}$ ions using both surface and bulk chemical measurement techniques (such as X-ray photoelectron spectrosocpy and x-ray absorption spectroscopy), surprising contradictory to our common sense that reduced form of $\mathrm{Ti}^{4+}$ ions would form under such condition. ${ }^{[4,18-20]}$ The hydrogen employed is found to play an important role in stabilizing the disordered layer, which makes a large contribution to the long-wavelength absorption and the enhanced charge separation and photocatalytic activity. ${ }^{[4,18,19]}$ Figure 3 shows a schematic illustration of the lattice and electronic structures, representative pictures, high-resultion transmission electron microscopy (HRTEM) images, ultraviolet-visible (UV-vis) and valence band $\mathrm{x}$-ray photoelectron spectroscopy (VBXPS) spectra of hydrogenated black and normal white $\mathrm{TiO}_{2}$ nanoparticles. ${ }^{[4]}$ Clearly, apparent changes can be seen after hydrogenation. Enhanced photocatalytic activities in producing hydrogen from water and in removing organic pollutants (methylene blue and phenol) are achieved with the hydrogenated crystalline/disordered core/shell nanoparticles. ${ }^{[4]}$

Since the striking discovery of the hydrogenated black $\mathrm{TiO}_{2}$ nanoparticles, extensive researches have been conducted to enrich our understanding in the preparation and properties of various hydrogenated $\mathrm{TiO}_{2}$ nanomaterials. ${ }^{[20-75]}$ Not surprisingly, it has been found that the extents of the color and optical spectrum changes, ${ }^{[20-75]}$ the formation of the crystalline/disordered core/shell nanostructures, ${ }^{[4,21-26]}$ the existence of possible $\mathrm{Ti}^{3+}$ and/or oxygen vacancies, ${ }^{[22-24,27-29]}$ Ti-OH groups, ${ }^{[22,25,26,28]}$ Ti-H groups, ${ }^{[22,25,26,30]}$ and the modification of the valence band, ${ }^{[4,18,23,28]}$ heavily depend on the characteristics of the starting $\mathrm{TiO}_{2}$ nanomaterials and the hydrogenation conditions. The former includes the fabrication history (which may affect the refined surface chemical properties possibly out of the detection limits of many analytical techniques), and the physical properties (size, shape, morphology, phase, crystallinity, etc) of the starting $\mathrm{TiO}_{2}$ nanomaterials. ${ }^{[28]}$ The latter includes the hydrogenation temperature, ${ }^{[31,41]}$ time,${ }^{[27]}$ hydrogen pressure, ${ }^{[32]}$ the composition of the atmosphere containing the hydrogen gas, ${ }^{[32]}$ the reactor type (gas-flow reactor versus sealed reactor), ${ }^{[47]}$ and the sample holder materials, etc. ${ }^{[20-57]}$ The difference in the fabrication process will naturally result in the difference in the characteristics of the hydrogenated $\mathrm{TiO}_{2}$ nanomaterials. This nature on one hand increases the complexity of the fabrication, but on the other hand, also increases the flexibility in the tuning of the characteristics of the hydrogenated $\mathrm{TiO}_{2}$ nanomaterials. Controlling the hydrogenation process can thus lead to various desirable properties and enhanced performance in many applications.

The photocatalytic performance of $\mathrm{TiO}_{2}$ nanoparticles is benefited from the formation of the crystalline/disordered core/shell nanostructure and the long-wavelength optical absorption of the hydrogenated black $\mathrm{TiO}_{2}$ nanoparticles. ${ }^{[4]}$ In the photocatalytic process, the photocatalyst (here, $\mathrm{TiO}_{2}$ ) absorbs 
light to produce excited electrons in the conduction band and holes in the valence band. The number of these excited electrons and holes are proportional to the amount of light the photocatalyst absorbs. The long-wavelength absorption of the hydrogenated black $\mathrm{TiO}_{2}$ nanoparticles would thus allow a large number of excited electrons and holes to be produced upon the beginning of the photocatalytic process. The crystalline core helps the effective separation of the excited electrons and holes. The difference in the electronic structures of the crystalline core and the disordered shell may generate mismatch and built-in electrical field ${ }^{[58]}$ to further facilitate charge separation and migration to the disordered shell, which may effectively trap those excited charges and extend their lifetime. The increased lifetime of the excited electrons and holes are confirmed with results from ultrafast experiments. ${ }^{[59]}$ Enhanced photocatalytic activities are observed on various hydrogenated $\mathrm{TiO}_{2}$ nanomaterials in producing hydrogen from water under sunlight and removing various organic pollutants. ${ }^{[4]}$ Large enhancements in the photocatalytic activity are most commonly seen under the UV light or simulated sunlight irradiation, ${ }^{[4,22,26,27,60,63]}$ and a large success has been achieved recently under visible light irradiation. ${ }^{[25,49,61]}$ Meanwhile, there are a few reports mentioning possible decrease in the photocatalytic activities, if the hydrogenated $\mathrm{TiO}_{2}$ nanomaterials are not properly prepared. ${ }^{[37,38]}$ So far, hydrogenation has been conducted on $\mathrm{TiO}_{2}$ nanoparticles, ${ }^{[4,21,31]}$ nanorods, ${ }^{[48]}$ nanotubes, ${ }^{[45]}$ nanowires, ${ }^{[46]}$ nanosheets, ${ }^{[35,36]}$ with anatase or rutile phase, ${ }^{[4,29,33]}$ under high-pressure, ${ }^{[4,21]}$ ambient pressure, ${ }^{[29,30,39]}$ or low-pressure ${ }^{[43]}$ pure hydrogen environment, or hydrogen-argon, ${ }^{[44-48]}$ hydrogen-nitrogen ${ }^{[52-54]}$ gas flow, in the temperature range from room temperature ${ }^{[21]}$ to $700{ }^{\circ} \mathrm{C}^{[27]}$ with a hydrogenation time from a few minutes ${ }^{[27]}$ to 20 days. ${ }^{[21]}$ With no doubt, we can image that the so-formed $\mathrm{TiO}_{2}$ nanomaterials will display variations in their characteristics and performances. A representative study on the hydrogenation condition on the photocatalytic activity is conducted by Liu et al. ${ }^{[32]}$ They compared the hydrogenated $\mathrm{TiO}_{2}$ nanotubes and nanorods treated under several conditions: (i) an anatase $\mathrm{TiO}_{2}$ nanotube layer (air); (ii) this layer converted with $\mathrm{Ar}$ (Ar) or $\mathrm{H}_{2} / \mathrm{Ar}\left(\mathrm{H}_{2} / \mathrm{Ar}\right)$; (iii) a high pressure $\mathrm{H}_{2}$ treatment (20 bar, $500{ }^{\circ} \mathrm{C}$ for $\left.1 \mathrm{~h}\right)\left(\mathrm{HP}-\mathrm{H}_{2}\right)$; and (iv) a high pressure $\mathrm{H}_{2}$ treatment but mild heating $\left(\mathrm{H}_{2}, 20\right.$ bar, $200{ }^{\circ} \mathrm{C}$ for 5 days) (Sci Ref. 4), and found that hydrogenated $\mathrm{TiO}_{2}$ nanotubes from high pressure $\mathrm{H}_{2}$ treatment had a high open circuit photocatalytic hydrogen production rate without the presence of a cocatalyst, in comparison with the low activity in other cases (Fig. 4). ${ }^{[32]}$ The variations in the photocatalytic activities of hydrogenated $\mathrm{TiO}_{2}$ nanomaterials seem reasonable taken into account the various fabrication conditions in those studies, and are more or less attributed in the literature to the variations of the amount of light absorbed, the existence of crystalline/disordered core/shell nanostructures, the existence of chemical defects $\left(\mathrm{Ti}^{3+}\right.$ and oxygen vacancies), the formation of $\mathrm{Ti}-\mathrm{OH}$ or Ti-H groups, the shift of valence/conduction band edges, and/ or the introduction of intra-band electronic states in the

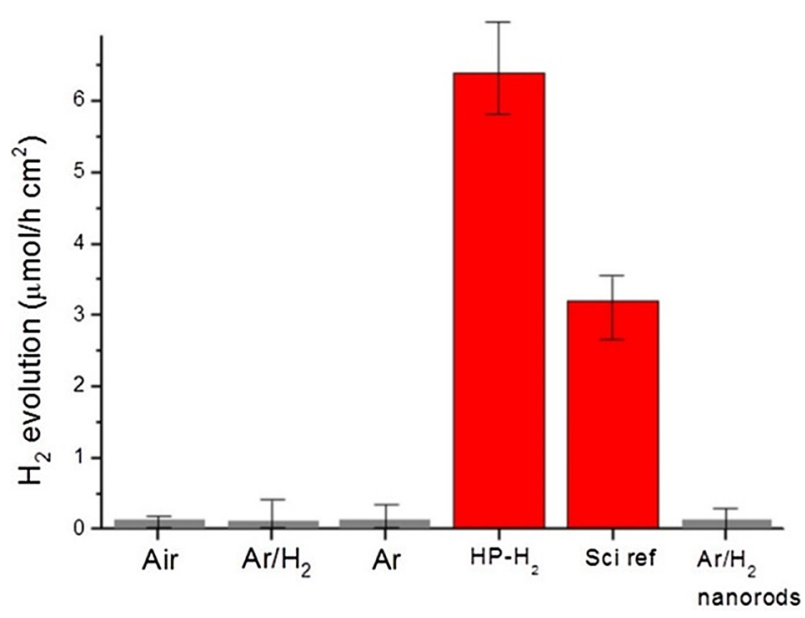

Figure 4. Photocatalytic $\mathrm{H}_{2}$ production under open circuit conditions in methanol/water (50/50 vol \%) with $\mathrm{TiO}_{2}$ nanotubes and nanorods treated in different atmospheres under AM1.5 $\left(100 \mathrm{~mW} / \mathrm{cm}^{2}\right)$ illumination. ${ }^{[32]}$ Air, heat treatment in air at $450{ }^{\circ} \mathrm{C}$; $\mathrm{Ar}$, heat treatment in pure argon at $500^{\circ} \mathrm{C} ; \mathrm{Ar} / \mathrm{H}_{2}$, heat treatment in $\mathrm{H}_{2} / \mathrm{Ar}(5 \mathrm{vol} \%)$ at $500^{\circ} \mathrm{C}$; $\mathrm{HP}-\mathrm{H}_{2}$, heat treatment in $\mathrm{H}_{2}$ at 20 bar at $500{ }^{\circ} \mathrm{C}$; heat treatment in $\mathrm{H}_{2}$ at 20 bar at $200{ }^{\circ} \mathrm{C}$ for 5 days (following Sci Ref. 4). ${ }^{[32]}$ Reprinted with permission from Ref. 32. Copyright 2014, American Chemical Society.

hydrogenated $\mathrm{TiO}_{2}$ nanomaterials. ${ }^{[20-75]}$ As these characteristics are primarily related to how the samples are made, the fabrication process seems to be an ultimately important aspect to achieve desirable photocatalytic performance.

The new characteristics of the hydrogenated $\mathrm{TiO}_{2}$ nanomaterials provide new application opportunities or enhanced performances for $\mathrm{TiO}_{2}$. For example, the shallow-trapped $\mathrm{Ti}^{4-n}$ defect sites in the hydrogenated $\mathrm{TiO}_{2}$ nanoparticles bring in catalytic activity in the conversion of ethylene to high density polyethylene under mild conditions (room temperature, low pressure, absence of any activator). ${ }^{[42]}$ And the oxygen vacancies produced in the hydrogenated $\mathrm{TiO}_{2}$ nanoparticles give catalytic activities in decompositing gaseous formaldehyde without light irradiation at room temperature. ${ }^{[48]}$ The improved electrical conductivity of the hydrogenated $\mathrm{TiO}_{2}$ nanorods benefits the photoelectrochemical sensing of various organic compounds: glucose, malonic acid and potassium hydrogen phthalate under visible light. ${ }^{[41]}$ Improved performances are observed when using hydrogenated $\mathrm{TiO}_{2}$ nanomaterials as the active anode materials in lithium-ion rechargeable batteries, due to the creation of oxygen vacancies, ${ }^{[28,44]}$ the existence of $\mathrm{Ti}^{3+}$ ions, ${ }^{[46]}$ the well-balanced $\mathrm{Li}^{+} / \mathrm{e}^{-}$diffusion, ${ }^{[44]}$ the increased electronic conductivity, ${ }^{[28,39,44,46]}$ reduced charge diffusion resistance, ${ }^{[76]}$ or the pseudocapacitive lithium storage on the disordered particle surface. ${ }^{[55]}$ For example, the short lithium-ion diffusion path and the high electronic conductivity in the hydrogenated mesoporous $\mathrm{TiO}_{2}$ microspheres improved the lithium-ion capacity and rate capability of mesoporous $\mathrm{TiO}_{2}$ microspheres (Fig. 5), ${ }^{[39]}$ and in $\mathrm{Li}_{4} \mathrm{Ti}_{5} \mathrm{O}_{12}$ nanowires. ${ }^{[46]}$ The increased densities of charge carrier and hydroxyl groups, 


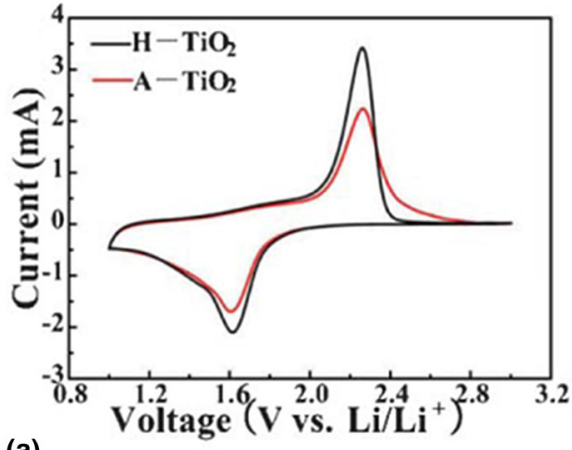

(a)

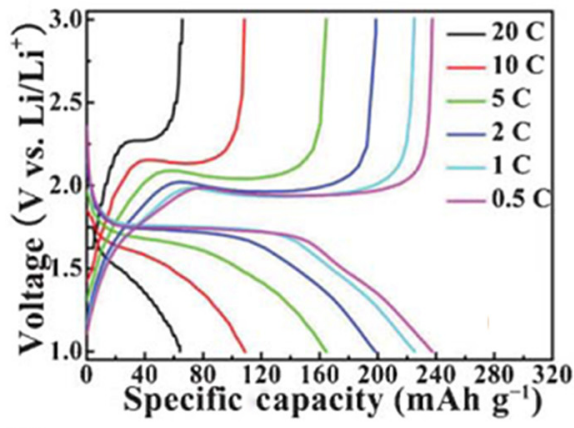

(c)

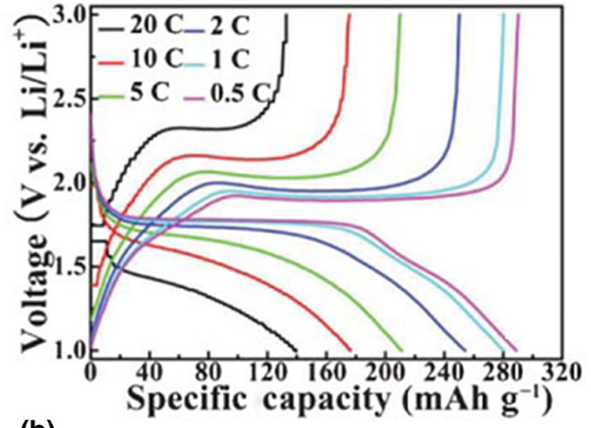

(b)

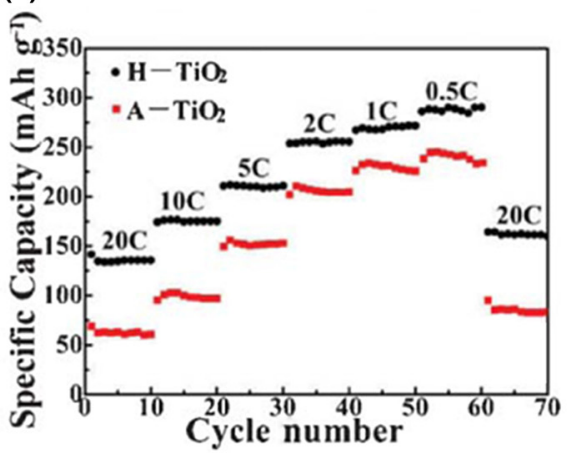

(d)

Figure 5. (a) Cyclic voltammetry profiles of the hydrogenated $\left(\mathrm{H}-\mathrm{TiO}_{2}\right)$ and pure $\left(\mathrm{A}-\mathrm{TiO}_{2}\right)$ anatase microspheres at a scan rate of $0.5 \mathrm{mV} / \mathrm{s}$. Galvanostatic discharge-charge profiles of the (b) $\mathrm{H}-\mathrm{TiO}_{2}$ and (c) $\mathrm{A}-\mathrm{TiO}_{2}$ microspheres at various rates. (d) Comparison of the rate performance of the $\mathrm{H}-\mathrm{TiO}_{2}$ and $\mathrm{A}-\mathrm{TiO}_{2}$ microspheres. ${ }^{[39]}$ Reprinted with permission from Ref. 39. Copyright 2013 The Royal Society of Chemistry.

and the higher electrical conductivity in the hydrogenated $\mathrm{TiO}_{2}$ nanotubes also help the supercapacitive performance of $\mathrm{TiO}_{2} \cdot{ }^{[17]}$ Meanwhile, these characteristics also help to deposit Pt nanoparticles on the surface and improve the performance and durability as electrode materials in fuel cells. ${ }^{[30]}$

The oxygen vacancies introduced to the hydrogenated $\mathrm{TiO}_{2}$ nanotubes lift the Fermi level, improve the electrical conductivity, and reduce the work function to decrease the field-penetration barrier at the surface resulting in easy electron emission in under electrical bias. ${ }^{[45]}$ As the crystalline/disordered core/shell nanostructure is formed for hydrogenated $\mathrm{TiO}_{2}$ nanoparticles, there is apparent electronic structural mismatch between the crystalline phase and the disordered phase..$^{[4,77,78]}$ The interface in between is expected to have structural and chemical defects with dangling bonds and charge imbalance. Meanwhile, the various defects help the charge diffusion and transport with smaller resistance. Interfacial band bending and polarization are expected in the boundaries between these phases. ${ }^{[79]}$ The propagation of the microwave electromagnetic field through the material will cause rapid switching of the polarizing direction and charge accumulation at these interfaces based on a collective-movement-of-interfacial-dipoles (CMID) mechanism. ${ }^{[77,78]}$ Hydrogenated $\mathrm{TiO}_{2}$ nanoparticles can thus show excellent microwave absorption performance. ${ }^{[77,78]}$ Changing the hydrogenation condition can tune the anatase/rutile ratios and the size of the individual core/shell nanoparticles to achieve microwave absorption with adjustable frequencies. ${ }^{[78]}$ Figure 6 shows a good example of the microwave absorption of hydrogenated $\mathrm{TiO}_{2}$ nanoparticles. ${ }^{[77,78]}$ This discovery has been expanded to hydrogenated $\mathrm{ZnO}$ and $\mathrm{BaTiO}_{3}$ nanoparticles for enhanced microwave absorption. ${ }^{[80,81]}$

Hydrogenated $\mathrm{TiO}_{2}$ nanoparticles have recently been demonstrated with promising medical application due to their extended absorption in the infrared region. ${ }^{[82,83]}$ They can efficiently convert the near-infrared light energy into thermal energy and produce localized heat island. ${ }^{[82]}$ After they are injected near the cancer cells and irradiated with near-infrared light, the locally produced heat can effectively kill the cancer cells without affecting the adjacent healthy cells. ${ }^{[82]}$ This process is named as photothermal therapy. Compared with the UV excitation requirement, the hydrogenated $\mathrm{TiO}_{2}$ only needs near-infrared excitation. This increases the penetration depth under the skin, and prevents the damage caused by the UV irradiation on the skin at the same time. Thus, hydrogenated $\mathrm{TiO}_{2}$ nanoparticles may prove to be very useful in medical applications.

\section{Other hydrogenated oxide nanomaterials ZnO}

Hydrogenated $\mathrm{ZnO}$ has also been studied as well. ${ }^{\left[{ }^{81,84-92]}\right.}$ Here, only some recent works are given as examples. Similar to 
(a)

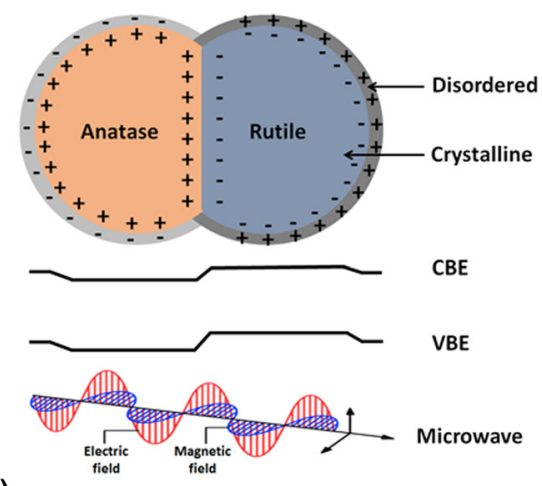

(b)

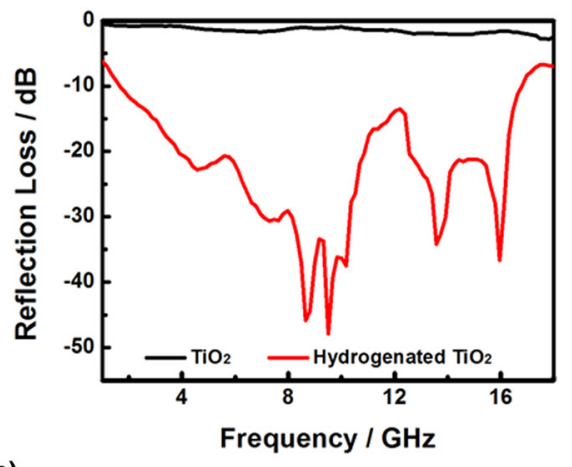

Figure 6. (a) The mechanism of collective interfacial polarization amplified microwave absorption (CIPAMA) of hydrogenated $\mathrm{TiO}_{2}$ nanoparticles. ${ }^{\text {[77] }}$ The collective movements of interfacial dipoles (CMID) at the anatase/rutile and crystalline/disordered interfaces amplify the response to the incoming electromagnetic field and thus induce enhanced microwave absorption performance. The positions of the electronic band structure of the disordered layer are assumed to lie between those of anatase and rutile phases. CBE: conduction band edge, VBE: valence band edge. Reprinted with permission from Ref. 77. Copyright 2013 Wiley-VCH. (b) Reflection loss of pristine and hydrogenated $\mathrm{TiO}_{2}$ nanocrystals. ${ }^{[78]}$ Reprinted with permission from Ref. 78 . Copyright 2014 Materials Research Society.

hydrogenation on $\mathrm{TiO}_{2}$, hydrogenation introduces visible-light absorption, ${ }^{[86]}$ oxygen vacancies, ${ }^{[86]}$ zinc vacancies, ${ }^{[86,91]}$ interstitial hydrogen, ${ }^{[84,85]}$ and increased carrier densities. ${ }^{[84]}$ The interstitial hydrogen increases the carrier densities, ${ }^{[84]}$ improves the charge transport in the bulk and the charge transfer at the solid/liquid interface. ${ }^{[85]}$ Meanwhile, the oxygen vacancies help the trapping of holes and thus the charge separation, and reduce the electron-hole recombination. These characteristics bring in higher photocatalytic activities in both photocatalytic hydrogen generation and pollution removal. Meanwhile, as hydrogenation improves the electrical conductivity ${ }^{[87]}$ and electrochemical activity of $\mathrm{ZnO}$, hydrogenated $\mathrm{ZnO}$-coated $\mathrm{MnO}_{2}$ nanowires have improved supercapacitor performance with enhanced capacity and stability. ${ }^{[88,89]}$ Under suitable hydrogenation conditions, the hydrogen introduced can passivate deep oxygen vacancies, but increase the shallow oxygen vacancies, thus, after hydrogenation, the defect-related peak at $2.10 \mathrm{eV}$ is no longer present in the room temperature photoluminescence spectrum, the peak intensity at $2.43 \mathrm{eV}$ is unchanged, and the intensity of the emission peak at $3.27 \mathrm{eV}$ increases significantly, resulting in an obvious emission spectrum and color change. ${ }^{[90]}$ Similar to hydrogenated $\mathrm{TiO}_{2}$, hydrogenated $\mathrm{ZnO}$ also displays impressive microwave absorption performance. ${ }^{[81]}$ In addition, hydrogenation seems to have a large impact on the ferromagnetism of $\mathrm{ZnO}$ nanoparticles. ${ }^{\text {[91] }}$ Hydrogenated $\mathrm{ZnO}$ nanoparticles display room-temperature ferromagnetism and their ferromagnetism can be switched between "on" and "off” by annealing in hydrogen or oxygen, respectively. ${ }^{[91]}$ The formation of $\mathrm{Zn}$ vacancy and $\mathrm{OH}$ bonding by hydrogenation is favored in the hydrogenation process due to the low formation energy, and lead to a magnetic moment of $0.57 \mu \mathrm{B}$, while the ferromagnetism is not induced by the oxygen vacancies. ${ }^{\left[{ }^{[1]}\right.}$ It is found that hydrogenation depends on the thickness of $\mathrm{ZnO}$ nanosheets. Hydrogenated $\mathrm{ZnO}$ nanosheets preserve the wurtzite configuration, instead of the polar $\{0001\}$ surfaces. Full hydrogenation is favorable for thinner nanosheets, while semihydrogenation is preferred for thicker nanosheets. The transition from semiconductor to magnetism depends upon surface hydrogenation and thickness. ${ }^{[92]}$

\section{$\mathrm{CeO}_{2}$ and $\mathrm{Ni}_{x} \mathrm{CeO}_{2+x}$}

Hydrogenation on $\mathrm{CeO}_{2}$ nanoparticles has also been recently studied. ${ }^{[93,94]}$ Grey $\mathrm{CeO}_{2}$ nanoparticles are obtained after hydrogenation due to the surface plasma resonance-like visiblelight absorption. ${ }^{[93]}$ Oxygen vacancies are created on the surface and in the bulk. Disordered surface is obtained after annealing in air. ${ }^{[93]}$ The hydrogenated $\mathrm{CeO}_{2}$ nanoparticles display enhanced performance as well as improved water resistance in photocatalytic oxidation of gaseous hydrocarbons. ${ }^{\text {[93] }}$ Hydrogenation has been employed in $\mathrm{Ni}_{x} \mathrm{CeO}_{2+x}$ nanoparticles to create unique metal/oxide interface. ${ }^{[94]}$ The formed $\mathrm{Ni} / \mathrm{CeO}_{2}$ interface modifies the hydrogen binding energy and facilitates the water dissociation to achieve a high activity in electrocatalytic hydrogen generation as shown in Fig. 7. ${ }^{[94]}$

\section{$\mathrm{VO}_{2}$}

$\mathrm{VO}_{2}$ is a material with strong correlation, and undergoes a metal-to-insulator transition at $67^{\circ} \mathrm{C}$ from a rutile metallic state to a monoclinic, insulating state. Hydrogenation can strongly modify the metal-insulator transition on the nanoscale. ${ }^{[95]}$ This transition becomes completely reversible with hydrogen doping and can eventually disappear with large doping content. ${ }^{[95]}$ The structure of the hydrogenated $\mathrm{VO}_{2}$ is distorted from the rutile structure and it energetically favors the metallicity. ${ }^{[95]}$ The hydrogen doping is believed by means of spillover and involves rapid diffusion along the rutile c-axis. ${ }^{[96-98]}$ 


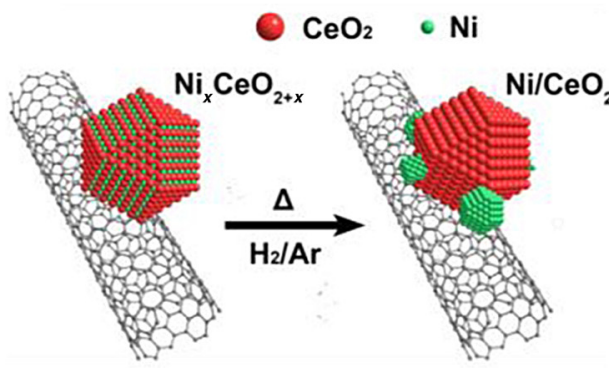

(a)

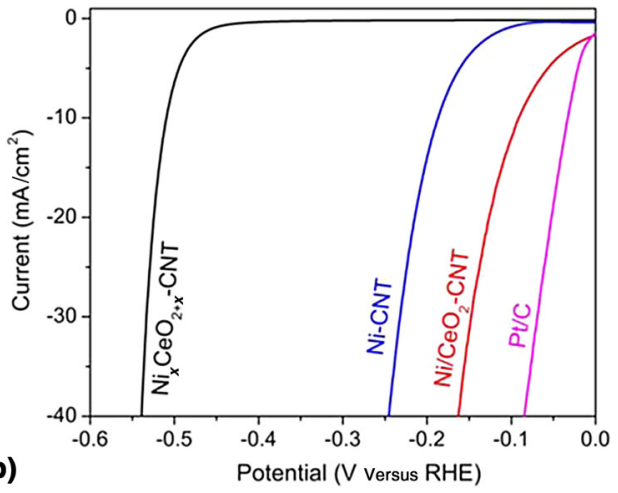

(b)

Figure 7. (a) Schematic illustration of the hydrogenation-induced structural change from $\mathrm{Ni}_{x} \mathrm{CeO}_{2+x}$ to $\mathrm{Ni} / \mathrm{CeO}_{2}$ on carbon nanotubes. (b) The electrochemical polarization curves for hydrogen evolution reactions on $\mathrm{Ni}_{x} \mathrm{CeO}_{2+x}-\mathrm{CNT}$, Ni/CeO${ }_{2}-\mathrm{CNT}$, Ni-CNT, and Pt/C electrodes. CNT: carbon nanotube. ${ }^{[94]}$ Reprinted with permission from Ref. 94. Copyright 2015, American Chemical Society.

\section{$\mathrm{WO}_{3}$}

Hydrogenation brings in similar optical, structural, and chemical property changes to $\mathrm{WO}_{3}$ as in $\mathrm{TiO}_{2}$ : optical absorption in the visible light region, obvious decrease in crystallinity, introduction of oxygen vacancies and lower valence-state metal ions $\mathrm{W}^{5+}$, enhanced photoelectrochemical activity and stability for water oxidation. ${ }^{[99]}$ The oxygen-deficient $\mathrm{WO}_{3}\left(\mathrm{WO}_{2.9}\right)$ displays enhanced activity in electrochemical hydrogen evolution reaction, due to the tailored electronic structure from local atomic structure modulations. ${ }^{[100]}$

\section{$\mathrm{MoO}_{3}$}

$\mathrm{MoO}_{3}$ can be used as a hole-injection layer in organic light emitting diodes and photovoltaics due to its decrease of the hole-injection/extraction energy barrier at the anode/organic interfaces. Hydrogenation treatment displays a unique advantage over other methods. ${ }^{[101]}$ Hydrogenation can create oxygen vacancies and hydroxyl groups in $\mathrm{MoO}_{3}$ and introduce bandgap states to improve the charge injection efficiency and thus the device performance. ${ }^{[101]}$

\section{TaON}

$\mathrm{TaON}$ has recently been shown as a promising photocatalyst in photocatalytic water splitting. Hydrogenation improves its visible-light absorption, increases charge density, reduces electron-hole recombination, and enhances the photocatalytic activity in photocatalytic hydrogen generation. ${ }^{[102]}$

\section{$\mathrm{TiOF}_{2}$}

$\mathrm{TiOF}_{2}$ has been studied as a possible anode materials for lithium-ion rechargeable batteries. Hydrogenation of $\mathrm{TiOF}_{2}$ nanoparticles leads to the formation of smaller particle sizes, i.e., along the (001) direction, increases oxygen vacancies, and improves the charge/discharge capacity and rate performance. ${ }^{[103]}$ Although structural defects seem to be introduced in the $\mathrm{TiOF}_{2}$ after hydrogenation, the hydrogenation does not reduce the electrical resistance, and increase the carrier density of the $\mathrm{TiOF}_{2}$ nanoparticles. ${ }^{[103]}$ The improved battery performance is mainly due to the increased electrochemically active surface areas and the reduced charge diffusion length benefited from the decreased particle size after hydrogenation. ${ }^{[103]}$

\section{$\mathrm{MnMoO}_{4}$}

Hydrogenation has been shown to improve the activity of electrochemically inert $\mathrm{MnMoO}_{4}$ for both hydrogen evolution and supercapacitive electrical energy storage. ${ }^{[104]}$ Hydrogenation can induce partial amorphorization in $\mathrm{MnMoO}_{4}$ and increase the electrochemical active surface area. The charge transfer resistance decreases for both capacitive charge storage and hydrogen evolution reaction (HER). As a result, the onset overpotential for the HER reaction is largely reduced and capacity for charge storage is largely enhanced at the same time. ${ }^{[104]}$

\section{NiO}

Ni and nickel hydr(oxide) compounds are explored as promising electrode materials for electrochemical production of hydrogen from water by electrolysis. ${ }^{[105]}$ Hydrogenation has been shown to convert $\mathrm{NiO}$ nanosheets into $\mathrm{Ni} / \mathrm{NiO}$ core/ shell nanosheets. ${ }^{[106]}$ In this case, NiO nanosheets are reduced to metallic Ni nanosheets first, and then oxidized to form crystalline/amorphous $\mathrm{Ni} / \mathrm{NiO}$ core/shell nanosheets when exposed to air. This unique structure is shown in Fig. 8. ${ }^{[106]}$ The amorphous $\mathrm{NiO}$ surface lowers the energy barrier for hydrogen evolution, reduces the desorption energy, while the metal core helps to reduce the electrical resistance. ${ }^{[106]}$ The hydrogenation also increases the electrochemically active surface area of the catalyst and the $\mathrm{Ni} / \mathrm{NiO}$ metal/metal oxide interface. Overall the catalytic activity in hydrogen evolution is enhanced. ${ }^{[106]}$

\section{$\mathrm{Co}_{3} \mathrm{O}_{4}$}

Similar to the changes induced on $\mathrm{NiO}$ nanosheets, hydrogenation is also shown to convert $\mathrm{Co}_{3} \mathrm{O}_{4}$ nanosheets to $\mathrm{Co} / \mathrm{Co}_{3} \mathrm{O}_{4}$ crystalline/amorphous core/shell nanosheets. ${ }^{[107]}$ These 


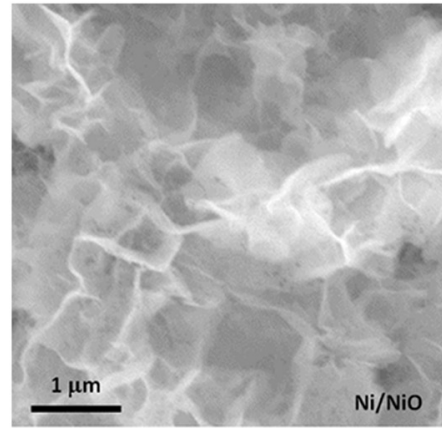

(a)

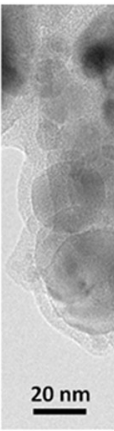

(b)

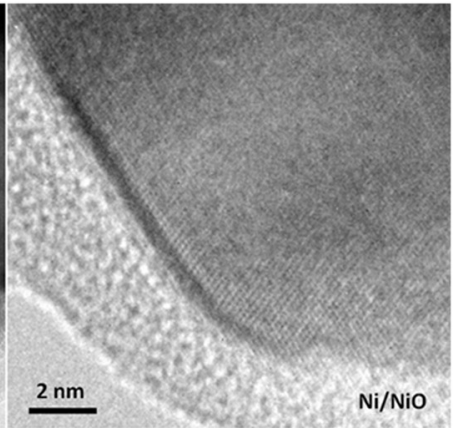

(c)

Figure 8. (a) SEM and (b, c) TEM images of hydrogenated Ni/NiO crystalline/amorphous core/shell nanosheets. ${ }^{[106]}$ Reprinted with permission from Ref. 106. Copyright 2015, Elsevier.

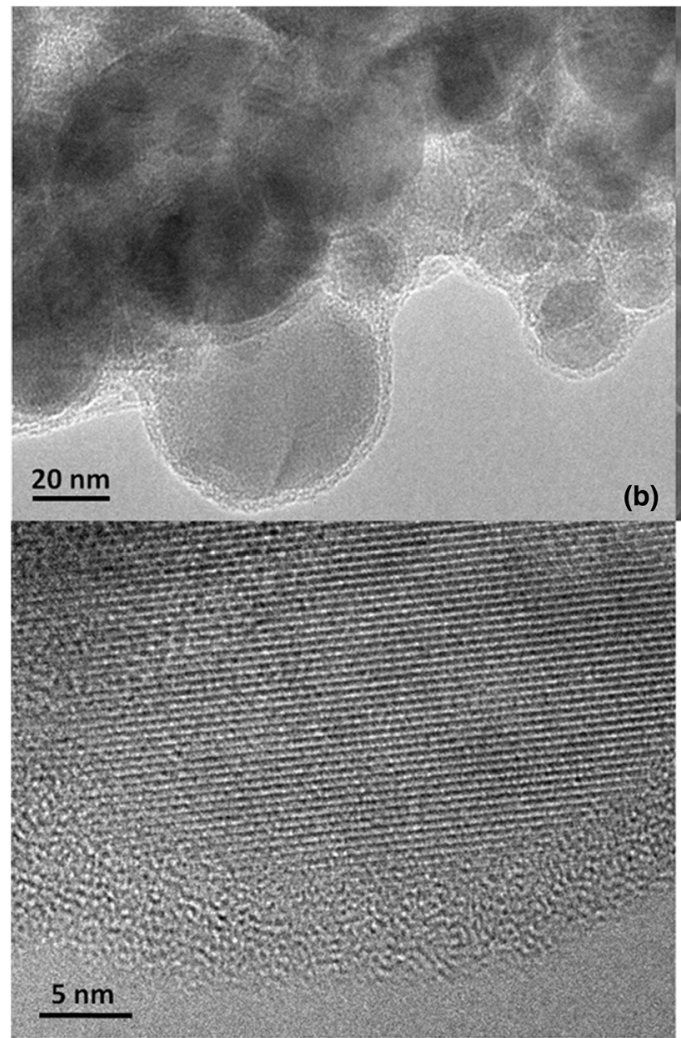

(c)
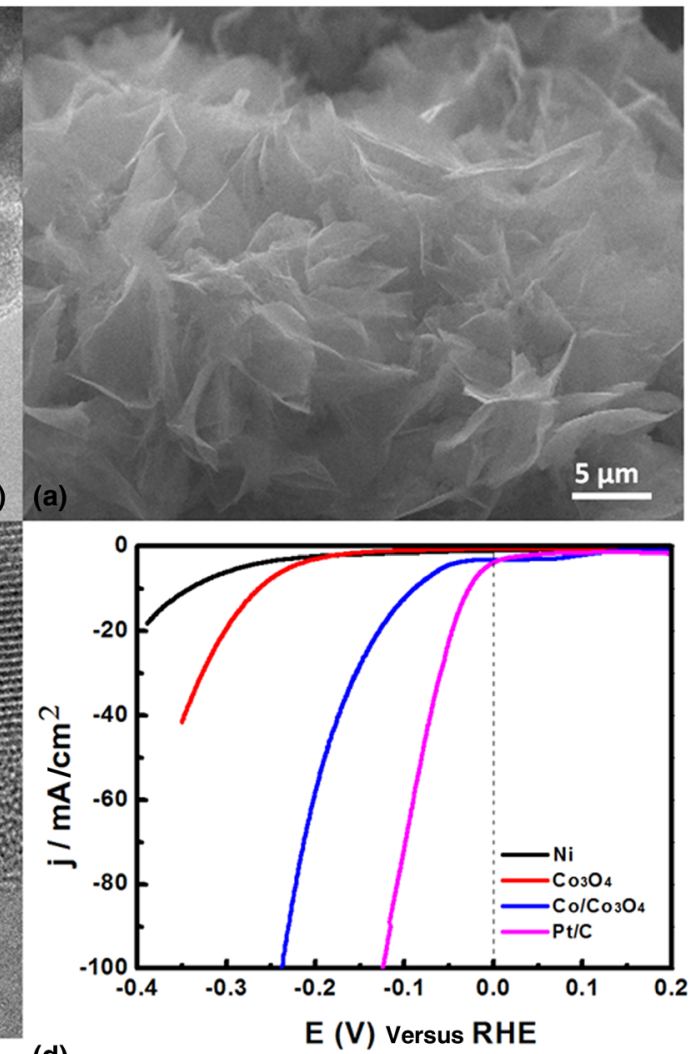

Figure 9. (a) SEM and (b, c) TEM images of hydrogenated $\mathrm{Co} / \mathrm{CO}_{3} \mathrm{O}_{4}$ crystalline/amorphous core/shell nanosheets, (d) The electrochemical polarization curves for hydrogen evolution reactions on $\mathrm{Ni}, \mathrm{CO}_{3} \mathrm{O}_{4}, \mathrm{Co} / \mathrm{CO}_{3} \mathrm{O}_{4}$, and $\mathrm{Pt} / \mathrm{C}{ }^{[107]}$ Reprinted with permission from Ref. 107. Copyright 2015, American Chemical Society.

nanosheets display impressive activity in electrochemical hydrogen evolution reaction with an overpotential of $\sim 90 \mathrm{mV}$ in $1 \mathrm{M} \mathrm{KOH}$ in achieving a current density of $10 \mathrm{~mA} / \mathrm{cm}^{2}$. [107] The good activity is likely due to the low gas desorption resistance and the fast charge-transfer kinetics on the surface of the electrode caused by the hydroxyl-enriched amorphous cobalt oxide caused by the hydrogenation treatment. ${ }^{[107]}$ Oxygen vacancies however, cause a poor performance. Typical microscopy images and the catalytic activity of the hydrogenated $\mathrm{Co} /$ $\mathrm{Co}_{3} \mathrm{O}_{4}$ nanosheets are shown in Fig. 9. ${ }^{[107]}$

\section{$\mathrm{Ni}_{x} \mathrm{Co}_{3-x} \mathrm{O}_{4}$}

Similar to $\mathrm{NiO}$ and $\mathrm{Co}_{3} \mathrm{O}_{4}$, hydrogenation on nanowires of their alloy $\mathrm{Ni}_{x} \mathrm{Co}_{3-x} \mathrm{O}_{4}$ can lead to the formation of $\mathrm{NiCo} / \mathrm{NiCoO} x$ 
heteronanostructure. ${ }^{[108]}$ And the corresponding activities in oxygen and hydrogen evolution reactions can be tuned after hydrogenation. ${ }^{[108]}$

\section{Summary and perspective}

In summary, hydrogenation has opened many opportunities in oxide nanomaterials and has become a new tool for scientists to manipulate the properties and applications of oxide and non-oxide nanomaterials. Hydrogenation treatment of oxide nanomaterials can introduce many unique structural, chemical, electronic, and other property changes. Those property changes can largely improve their performance in many applications such as photocatalysis, electrocatalysis, photoelectrocatalysis, rechargeable batteries, supercapacitors, and also trigger some new applications such as photothermal image/therapy, field emission, ferromagnetism, and microwave absorption. Further studies may reveal more interesting properties and applications.

Tuning the hydrogenation condition can control the chemical reaction and the final product, and generate new structures and chemical composition. However, understanding of the hydrogenation reaction itself is far from satisfactory, although the property changes caused by the hydrogenation treatment are well studied. Studies on the chemical reaction kinetics, in situ or ex situ, will help us to better understand and thus control the property changes by hydrogenation, which may reveal new applications. The large visible-light absorption induced by hydrogenation in some oxide nanomaterials has not yet been efficiently utilized. Continuing exploring the synthetic approaches and procedures may provide a promising future as seen from the recent developments, which sometimes are accompanied with frustrations and excitements. The mechanical and biological properties of the hydrogenated oxide nanomaterials are not yet studied. Studies in those properties may reveal better or new applications. For example, the crystalline/disordered nanoparticles may be better building units for constructing stronger bulk materials. In addition, the surface wettability of hydrogenated nanoparticles is not yet explored. As hydrogenation changes the oxygen vacancies and hydroxyl groups, it is expected that the surface wettability will be affected as well. Meanwhile, expansion of hydrogenation treatment to other oxide and non-oxide nanomaterials or their combinations may open new opportunities. For example, hydrogenation of FeP nanoparticles leads to an apparent reduction in the overpotential for hydrogen evolution, ${ }^{[109]}$ and complex metal/oxide $\mathrm{FeNi}_{3} / \mathrm{NiFeO}_{x}$ nanocomposites are obtained as highly efficient bifunctional electrocatalysts for overall water splitting with a small potential of $1.55 \mathrm{~V}$ to reach the critical current density of $10 \mathrm{~mA} / \mathrm{cm}^{2}$ after hydrogenation on $\mathrm{NiFeO}_{x}$ nanosheets. ${ }^{[10]}$

\section{Acknowledgments}

X. C. thanks the financial support from the U.S. National Science Foundation (DMR-1609061), and the College of Arts and Sciences, University of Missouri-Kansas City. X. Y. thanks the funds provided by the University of Missouri-Kansas City, School of Graduate Studies. L. Tian and X. Tan appreciate the China Scholarship Council for financial support. L. L. acknowledges the support from the National Science Fund for Distinguished Young Scholars of China (No. 61525404).

\section{References}

1. C.B. Murray, C.R. Kagan, and M.G. Bawendi: Synthesis and characterization of monodisperse nanocrystals and close-packed nanocrystal assemblies. Annual Rev. Mater. Sci. 30, 545 (2000).

2. C. Burda, X. Chen, R. Narayanan, and M.A. El-Sayed: Chemistry and properties of nanocrystals of different shapes. Chem. Rev. 105, 1025 (2005).

3. P. Alivisatos: Perspectives on the physical chemistry of semiconductor nanocrystals. J. Phys. Chem. 100, 13226 (1996).

4. X. Chen, L. Liu, P.Y. Yu, and S.S. Mao: Increasing solar absorption for photocatalysis with black hydrogenated titanium dioxide nanocrystals. Science 331, 746 (2011).

5. D.C. Cronemeyer and M.A. Gilleo: The optical absorption and photoconductivity of rutile. Phys. Rev. 82, 975 (1951).

6. D.C. Cronemeyer: Infrared absorption of reduced rutile Ti single crystals. Phys. Rev. 113, 1222 (1959).

7. T. Sekiya, T. Yagisawa, N. Kamiya, D. Das Mulmi, S. Kurita, Y. Murakami, and $\mathrm{T}$. Kodaira: Defects in anatase $\mathrm{TiO}_{2}$ single crystal controlled by heat treatments. J. Phys. Soc. Jpn. 73, 703 (2004).

8. R.R. Hasiguti and E. Yagi: Electrical conductivity below $3 \mathrm{~K}$ of slightly reduced oxygen-deficient rutile $\mathrm{TiO}_{2-x}$. Phys. Rev. B 49, 7251 (1994).

9. E. Yagi, R.R. Hasiguti, and M. Aono: Electronic conduction above $4 \mathrm{~K}$ of slightly reduced oxygen-deficient rutile $\mathrm{TiO}_{2-x}$. Phys. Rev. B 54, 7945 (1996).

10. V.E. Henrich and R.L. Kurtz: Surface electronic structure of $\mathrm{TiO}_{2}$ : atomic geometry, ligand coordination, and the effect of adsorbed hydrogen. Phys. Rev. 23, 6280 (1981).

11. W.J. Lo, Y.W. Chung, and G.A. Somorjai: Electron spectroscopy studies of the chemisorption of $\mathrm{O}_{2}, \mathrm{H}_{2}$ and $\mathrm{H}_{2} \mathrm{O}$ on the $\mathrm{TiO}_{2}(100)$ surfaces with varied stoichiometry: evidence for the photogeneration of $\mathrm{Ti}^{+3}$ and for its importance in chemisorption. Surf. Sci. 71, 199 (1978).

12. J.-M. Pan, B.L. Maschhoff, U. Diebold, and T.E. Madey: Interaction of water, oxygen, and hydrogen with $\mathrm{TiO}_{2}(110)$ surfaces having different defect densities. J. Vac. Sci. Technol. A 10, 2470 (1992).

13. M.S. Lazarus and T.K. Sham: X-ray photoelectron spectroscopy (XPS) studies of hydrogen reduced rutile $\left(\mathrm{TiO}_{2-\chi}\right)$ surfaces. Chem. Phys. Lett. 92, 670 (1982).

14. Q. Zhong, J.M. Vohs, and D.A. Bonnell: Local structure of defects on hydrogen and vacuum reduced $\mathrm{TiO}_{2}$. J. Am. Ceram. Soc. 76, 1137 (1993).

15. A. Heller, Y. Degani, D.W. Johnson, and P.K. Gallagher: Controlled suppression or enhancement of the photoactivity of titanium dioxide (rutile) pigment. J. Phys. Chem. 91, 5987 (1987).

16. H. Liu, H.T. Ma, X.Z. Li, W.Z. Li, M. Wu, and X.H. Bao: The enhancement of $\mathrm{TiO}_{2}$ photocatalytic activity by hydrogen thermal treatment. Chemosphere 50, 39 (2003).

17. X. Lu, G. Wang, T. Zhai, M. Yu, J. Gan, Y. Tong, and Y. Li: Hydrogenated $\mathrm{TiO}_{2}$ nanotube arrays for supercapacitors. Nano Lett. 12, 1690 (2012).

18. X. Chen, L. Liu, Z. Liu, M.A. Marcus, W.-C. Wang, N.A. Oyler, M.E. Grass, B. Mao, P.-A. Glans, P.Y. Yu, J. Guo, and S.S. Mao: Properties of disorder-engineered black titanium dioxide nanoparticles through hydrogenation. Sci. Rep. 3, 1510 (2013).

19. L. Liu, P.P. Yu, X. Chen, S.S. Mao, and D.Z. Shen: Hydrogenation and disorder in engineered black $\mathrm{TiO}_{2}$. Phys. Rev. Lett. 111, 065505 (2013).

20. T. Xia and $X$. Chen: Revealing the structural properties of hydrogenated black $\mathrm{TiO}_{2}$ nanocrystals. J. Mater. Chem. A 1, 2983 (2013).

21. H. Lu, B. Zhao, R. Pan, J. Yao, J. Qiu, L. Luo, and Y. Liu: Safe and facile hydrogenation of commercial Degussa P25 at room temperature with enhanced photocatalytic activity. RSC Adv. 4, 1128 (2014).

22. W. Wang, Y. Ni, C. Lu, and Z. Xu: Hydrogenation of TiO2 nanosheets with exposed $\{001\}$ facets for enhanced photocatalytc activity. RSC Adv. 2, 8286 (2012) 
23. A. Naldoni, M. Allieta, S. Santangelo, M. Marelli, F. Fabbri, S. Cappelli, C. L. Bianchi, R. Psaro, and V. Dal Santo: Effect of nature and location of defects on bandgap narrowing in black $\mathrm{TiO}_{2}$ nanoparticles. J. Am. Chem. Soc. 134, 7600 (2012)

24. X. Jiang, Y. Zhang, J. Jiang, Y. Rong, Y. Wang, Y. Wu, and C. Pan: Characterization of oxygen vacancy associates within hydrogenated $\mathrm{TiO}_{2}$ : a positron annihilation study. J. Phys. Chem. C116, 22619 (2012).

25. Z. Zheng, B. Huang, J. Lu, Z. Wang, X. Qin, X. Zhang, Y. Dai, and M.-H. Whangbo: Hydrogenated titania: synergy of surface modification and morphology improvement for enhanced photocatalytic activity. Chem. Commun. 48, 5733 (2012).

26. Z. Wang, C. Yang, T. Lin, H. Yin, P. Chen, D. Wan, F. Xu, F. Huang, J. Lin, $X$. Xie, and M. Jiang: H-doped black titania with very high solar absorption and excellent photocatalysis enhanced by localized surface plasmon resonance. Adv. Funct. Mater. 23, 5444 (2013).

27. X. Yu, B. Kim, and Y.K. Kim: Highly enhanced photoactivity of anatase $\mathrm{TiO}_{2}$ nanocrystals by controlled hydrogenation-induced surface defects. ACS Catal. 3, 2479 (2013).

28. Z. Lu, C.-T. Yip, L. Wang, H. Huang, and L. Zhou: Hydrogenated $\mathrm{TiO}_{2}$ nanotube arrays as high-rate anodes for lithium-ion microbatteries. ChemPlusChem 77, 991 (2012).

29. J.E. Rekoske and M.A. Barteau: Isothermal reduction kinetics of titanium dioxide-based materials. J. Phys. Chem. B 101, 1113 (1997).

30. C. Zhang, H. Yu, Y. Li, Y. Gao, Y. Zhao, W. Song, Z. Shao, and B. Yi: Supported noble metals on hydrogen-treated TiO2 nanotube arrays as highly ordered electrodes for fuel cells. ChemSusChem 6, 659 (2013).

31. C. Sun, Y. Jia, X.-H. Yang, H.-G. Yang, X. Yao, G.Q. (Max) Lu, A. Selloni, and S.C. Smith: Hydrogen incorporation and storage in well-defined nnanocrystals of anatase titanium dioxide. J. Phys. Chem. C 115, 25590 (2011)

32. N. Liu, C. Schneider, D. Freitag, M. Hartmann, U. Venkatesan, J. Muller, E. Spiecker, and P. Schmuki: Black $\mathrm{TiO}_{2}$ nanotubes: cocatalyst-free open-circuit hydrogen generation. Nano Lett. 14, 3309 (2014)

33. J. Qiu, S. Li, E. Gray, H. Liu, Q.-F. Gu, C. Sun, C. Lai, H. Zhao, and $\mathrm{S}$. Zhang: Hydrogenation synthesis of blue $\mathrm{TiO}_{2}$ for high-performance lithium-ion batteries. J. Phys. Chem. C 118, 8824 (2014)

34. J. Qiu, C. Lai, E. Gray, S. Li, S. Qiu, E. Strounina, C. Sun, H. Zhao, and $\mathrm{S}$. Zhang: Blue hydrogenated lithium titanate as a high-rate anode material for lithium-ion batteries. J. Mater. Chem. A 2, 6353 (2014).

35. W. Wang, C. Lu, Y. Ni, M. Su, and Z. Xu: A new sight on hydrogenation of $\mathrm{F}$ and $\mathrm{N}-\mathrm{F}$ doped $\{001\}$ facets dominated anatase $\mathrm{TiO}_{2}$ for efficient visible light photocatalyst. Appl. Catal. B 127, 28 (2012).

36. W. Wang, Y. Ni, C. Lu, and Z. Xu: Hydrogenation temperature related inner structures and visible-light-driven photocatalysis of $\mathrm{N}-\mathrm{F}$ co-doped $\mathrm{TiO}_{2}$ nanosheets. Appl. Surf. Sci. 290, 125 (2014).

37. T. Leshuk, S. Linley, and F. Gu: Hydrogenation processing of $\mathrm{TiO}_{2}$ nanoparticles. Can. J. Chem. Eng. 91, 799 (2013).

38. T. Leshuk, R. Parviz, P. Everett, H. Krishnakumar, R.A. Varin, and F. Gu: Photocatalytic activity of hydrogenated $\mathrm{TiO}_{2}$. ACS Appl. Mater. Interfaces 5, 1892 (2013).

39. G. Li, Z. Zhang, H. Peng, and K. Chen: Mesoporous hydrogenated $\mathrm{TiO}_{2}$ microspheres for high rate capability lithium ion batteries. RSC Adv. $\mathbf{3}$, 11507 (2013)

40. S. Li, J. Qiu, M. Ling, F. Peng, B. Wood, and S. Zhang: Photoelectrochemical characterization of hydrogenated $\mathrm{TiO}_{2}$ nanotubes as photoanodes for sensing applications. ACS Appl. Mater. Interfaces 5, 11129 (2013).

41. G. Wang, H. Wang, Y. Ling, Y. Tang, X. Yang, R.C. Fitzmorris, C. Wang, J.Z. Zhang, and Y. Li: Hydrogen-treated $\mathrm{TiO}_{2}$ nanowire arrays for photoelectrochemical water splitting. Nano Lett. 11, 3026 (2011).

42. C. Barzan, E. Groppo, S. Bordiga, and A. Zecchina: Defect sites in $\mathrm{H}_{2}$-reduced $\mathrm{TiO}_{2}$ convert ethylene to high density polyethylene without activator. ACS Catal. 4, 986 (2014).

43. Z. Liang, G. Zheng, W. Li, Z.W. Seh, H. Yao, K. Yan, D. Kong, and Y. Cui: Sulfur cathodes with hydrogen reduced titanium dioxide inverse opal structure. ACS Nano 8, 5249 (2014).

44. J.-Y. Shin, J.H. Joo, D. Samuelis, and J. Maier: Oxygen-deficient $\mathrm{TiO}_{2-\delta}$ nanoparticles via hydrogen reduction for high rate capability lithium batteries. Chem. Mater. 24, 543 (2012).
45. W.-D. Zhu, C.-W. Wang, J.-B. Chen, D.-S. Li, F. Zhou, and H.-L. Zhang: Enhanced field emission from hydrogenated $\mathrm{TiO}_{2}$ nanotube arrays. Nanotechnology 23, 455204 (2012).

46. L. Shen, E. Uchaker, X. Zhang, and G. Cao: Hydrogenated $\mathrm{Li}_{4} \mathrm{Ti}_{5} \mathrm{O}_{12}$ nanowire arrays for high rate lithium ion batteries. Adv. Mater. 24, 6502 (2012).

47. A. Danon, K. Bhattacharyya, B.K. Vijayan, J. Lu, D.J. Sauter, K.A. Gray, P. C. Stair, and E. Weitz: Effect of reactor materials on the properties of titanium oxide nanotubes. ACS Catal. 2, 45 (2012).

48. S. Zhang, S. Zhang, B. Peng, H. Wang, H. Yu, H. Wang, and F. Peng: High performance hydrogenated $\mathrm{TiO}_{2}$ nanorod arrays as a photoelectrochemical sensor for organic compounds under visible light. Electrochem. Commun. 40, 24 (2014).

49. L. Zeng, W. Song, M. Li, D. Zeng, and C. Xie: Catalytic oxidation of formaldehyde on surface of $\mathrm{H}-\mathrm{TiO}_{2} / \mathrm{H}-\mathrm{C}-\mathrm{TiO}_{2}$ without light illumination at room temperature. Appl. Catal. B 147, 490 (2014).

50. J. Wang, L. Shen, P. Nie, G. Xu, B. Ding, S. Fang, H. Dou, and X. Zhang: Synthesis of hydrogenated $\mathrm{TiO}_{2}$-reduced-graphene oxide nanocomposites and their application in high rate lithium ion batteries. J. Mater. Chem. A 2, 9150 (2014).

51. S. Hoang, S.P. Berglund, N.T. Hahn, A.J. Bard, and C.B. Mullins: Enhancing visible light photo-oxidation of water with $\mathrm{TiO}_{2}$ nanowire arrays via cotreatment with $\mathrm{H}_{2}$ and $\mathrm{NH}_{3}$ : synergistic effects between $\mathrm{Ti}^{3+}$ and N. J. Am. Chem. Soc. 134, 3659 (2012).

52. H. He, K. Yang, N. Wang, F. Luo, and H. Chen: Hydrogenated $\mathrm{TiO}_{2}$ film for enhancing photovoltaic properties of solar cells and self-sensitized effect. J. Appl. Phys. 114, 213505 (2013).

53. D. Wang, X. Zhang, P. Sun, S. Lu, L. Wang, C. Wang, and Y. Liu: Photoelectrochemical water splitting with rutile $\mathrm{TiO}_{2}$ nanowires array: synergistic effect of hydrogen treatment and surface modification with anatase nanoparticles. Electrochim. Acta 130, 290 (2014).

54. Y. Zhu, D. Liu, and M. Meng: $\mathrm{H}_{2}$ spillover enhanced hydrogenation capability of $\mathrm{TiO}_{2}$ used for photocatalytic splitting of water: a traditional phenomenon for new applications. Chem. Commun. 50, 6049 (2014).

55. S.-T. Myung, M. Kikuchi, C.S. Yoon, H. Yashiro, S.-J. Kim, Y.-K. Sun, and B. Scrosati: Black anatase titania enabling ultra high cycling rates for rechargeable lithium batteries. Energy Environ. Sci. 6, 2609 (2013).

56. F. Teng, M. Li, C. Gao, G. Zhang, P. Zhang, Y. Wang, L. Chen, and E. Xie: Preparation of black $\mathrm{TiO}_{2}$ by hydrogen plasma assisted chemical vapor deposition and its photocatalytic activity. Appl. Catal. B 148-149, 339 (2014).

57. Y. Yan, B. Hao, D. Wang, G. Chen, E. Markweg, and A. Albrecht, and $P$. Schaaf: Understanding the fast lithium storage performance of hydrogenated $\mathrm{TiO}_{2}$ nanoparticles. J. Mater. Chem. A 1, 14507 (2013).

58. T. Xia, W. Zhang, J. Murowchick, G. Liu, and X. Chen: Built-in electric field-assisted surface-amorphized nanocrystals for high-rate lithium-ion battery. Nano Lett. 13, 5289 (2013).

59. F.M. Pesci, G. Wang, D.R. Klug, Y. Li, and A.J. Cowan: Efficient suppression of electron-hole recombination in oxygen-deficient hydrogentreated $\mathrm{TiO}_{2}$ nanowires for photoelectrochemical water splitting. J. Phys. Chem. C 117, 25837 (2013).

60. K. Zhang, L. Wang, J.K. Kim, M. Ma, G. Veerappan, C.-L. Lee, K.-J. Kong, H. Lee, and J.H. Park: An order/disorder/water junction system for highly efficient co-catalyst-free photocatalytic hydrogen generation. Energy Environ. Sci. 9, 499 (2016).

61. A. Sinhamahapatra, J.-P. Jeon, and J.-S. Yu: A new approach to prepare highly active and stable black titania for visible light-assisted hydrogen production. Energy Environ. Sci. 8, 3539 (2015).

62. J. Cai, Y. Zhu, D. Liu, M. Meng, Z. Hu, and Z. Jiang: Synergistic effect of titanate-anatase heterostructure and hydrogenation-induced surface disorder on photocatalytic water splitting. ACS Catal. 5, 1708 (2015).

63. T.-D. Nguyen-Phan, S. Luo, Z. Liu, A.D. Gamalski, J. Tao, W. Xu, E.A. Stach, D.E. Polyansky, S.D. Senanayake, E. Fujita, and J.A. Rodriguez: Striving toward noble-metal-free photocatalytic water splitting: the hydrogenatedgraphene- $\mathrm{TiO}_{2}$ prototype. Chem. Mater. 27, 6282 (2015).

64. T. Su, Y. Yang, Y. Na, R. Fan, L. Li, L. Wei, B. Yang, and W. Cao: An insight into the role of oxygen vacancy in hydrogenated $\mathrm{TiO}_{2}$ nanocrystals in the performance of dye-sensitized solar cells. ACS Appl. Mater. Interfaces 7, 3754 (2015). 
65. L.H. Cui, Y. Wang, X. Shu, J.F. Zhang, C.P. Yu, J.W. Cui, H.M. Zheng, Y. Zhang, and Y.C. Wu: Supercapacitive performance of hydrogenated $\mathrm{TiO}_{2}$ nanotube arrays decorated with nickel oxide Nanoparticles. $R S C$ Adv. 6, 12185 (2016).

66. J. Cai, Y. Wang, Y. Zhu, M. Wu, H. Zhang, X. Li, Z. Jiang, and M. Meng: In situ formation of disorder-engineered $\mathrm{TiO}_{2}(\mathrm{~B})$-anatase heterophase junction for enhanced photocatalytic hydrogen evolution. ACS Appl. Mater. Interfaces 7, 24987 (2015).

67. S. Yang, Y. Lin, X. Song, P. Zhang, and L. Gao: Covalently coupled ultrafine $\mathrm{H}-\mathrm{TiO}_{2}$ nanocrystals/nitrogen-doped graphene hybrid materials for high-performance supercapacitor. ACS Appl. Mater. Interfaces 7, $17884(2015)$.

68. J. Zheng, Y. Liu, G. Ji, P. Zhang, X. Cao, B. Wang, C. Zhang, X. Zhou, $Y$. Zhu, and D. Shi: Hydrogenated oxygen-deficient blue anatase as anode for high-performance lithium batteries. ACS Appl. Mater. Interfaces 7, 23431 (2015).

69. E.M. Samsudin, S.B.A. Hamid, J.C. Juan, W.J. Basirun, and G. Centi: Synergetic effects in novel hydrogenated $\mathrm{F}$-doped $\mathrm{TiO}_{2}$ photocatalysts. Appl. Surf. Sci. 370, 380 (2016).

70. A.P. Singh, N. Kodan, B.R. Mehta, A. Dey, and S. Krishnamurthy: In-situ plasma hydrogenated $\mathrm{TiO}_{2}$ thin films for enhanced photoelectrochemical properties. Mater. Res. Bull. 76, 284 (2016).

71. G. Zhu, Y. Shan, T. Lin, W. Zhao, J. Xu, Z. Tian, H. Zhang, C. Zheng, and F. Huang: Hydrogenated blue titania with high solar absorption and greatly improved photocatalysis. Nanoscale 8, 4705 (2016).

72. L.-B. Mo, Y. Wang, Y. Bai, Q.-Y. Xiang, Q. Li, W.-Q. Yao, J.-O. Wang, K. Ibrahim, H.-H. Wang, C.-H. Wan, and J.-L. Cao: Hydrogen impurity defects in rutile $\mathrm{TiO}_{2}$. Sci. Rep. 5, 17634 (2015).

73. M.I. Nandasiri, V. Shutthanandan, S. Manandhar, A.M. Schwarz, L. Oxenford, J.V. Kennedy, S. Thevuthasan, and M.A. Henderson: Instability of hydrogenated $\mathrm{TiO}_{2}$. J. Phys. Chem. Lett. 6, 4627 (2015).

74. N. Wang, J. Yue, L. Chen, Y. Qian, and J. Yang: Hydrogenated $\mathrm{TiO}_{2}$ branches coated $\mathrm{Mn}_{3} \mathrm{O}_{4}$ nanorods as an advanced anode material for lithium ion batteries. ACS Appl. Mater. Interfaces 7, 10348 (2015).

75. X. Wang, S. Zhang, H. Wang, H. Yu, H. Wang, S. Zhang, and F. Peng: Visible light photoelectrochemical properties of a hydrogenated $\mathrm{TiO}_{2}$ nanorod film and its application in the detection of chemical oxygen demand. RSC Adv. 5, 76315 (2015).

76. T. Xia, W. Zhang, Z. Wang, Y. Zhang, X. Song, J. Murowchick, V. Battaglia, G. Liu, and X. Chen: Amorphous carbon-coated $\mathrm{TiO}_{2}$ nanocrystals for improved lithium-ion battery and photocatalytic performance. Nano Energy 6, 109 (2014).

77. T. Xia, C. Zhang, N.A. Oyler, and X. Chen: Hydrogenated $\mathrm{TiO}_{2}$ nanocrystals: a novel microwave absorbing material. Adv. Mater. 25, 6905 (2013).

78. T. Xia, C. Zhang, N.A. Oyler, and X. Chen: Enhancing microwave absorption of $\mathrm{TiO}_{2}$ nanocrystals via hydrogenation. J. Mater. Res. 29, 2198 (2014).

79. J. Dong, R. Ullal, J. Han, S. Wei, X. Ouyang, J. Dong, and W. Gao: Partially crystallized $\mathrm{TiO}_{2}$ for microwave absorption. J. Mater. Chem. A 3, 5285 (2015).

80. L. Tian, X. Yan, J. Xu, P. Wallenmeyer, J.B. Murowchick, L. Liu, and $X$. Chen: Effect of hydrogenation on the microwave absorption properties of $\mathrm{BaTiO}_{3}$ nanoparticles. J. Mater. Chem. A 3, 12550 (2015).

81. T. Xia, Y. Cao, N.A. Oyler, J. Murowchick, L. Liu, and X. Chen: Strong microwave absorption of hydrogenated wide bandgap semiconductor nanoparticles. ACS Appl. Mater. Interfaces 7, 10407 (2015).

82. W. Ren, Y. Yan, L. Zeng, Z. Shi, A. Gong, P. Schaaf, D. Wang, J. Zhao, B. Zou, H. Yu, G. Chen, E.M.B. Brown, and A. Wu: A near infrared light triggered hydrogenated black $\mathrm{TiO}_{2}$ for cancer photothermal therapy. $\mathrm{AdV}$. Healthcare Mater. 4, 1526 (2015).

83. J. Mou, T. Lin, F. Huang, H. Chen, and J. Shi: Black titania-based theranostic nanoplatform for single NIR laser induced dual-modal imagingguided PTT/PDT. Biomater. 84, 13 (2016).

84. Y.M. Strzhemechny, H.L. Mosbacker, D.C. Look, D.C. Reynolds, C.W. Litton, N.Y. Garces, N.C. Giles, L.E. Halliburton, S. Niki, and L.J. Brillson: Remote hydrogen plasma doping of single crystal $\mathrm{ZnO}$. Appl. Phys. Lett. 84, 2545 (2004).
85. X. Lu, G. Wang, S. Xie, J. Shi, W. Li, Y. Tong, and Y. Li: Efficient photocatalytic hydrogen evolution over hydrogenated $\mathrm{ZnO}$ nanorod arrays. Chem. Commun. 48, 7717 (2012).

86. T. Xia, P. Wallenmeyer, A. Anderson, J. Murowchick, L. Liu, and X. Chen: Hydrogenated black $\mathrm{ZnO}$ nanoparticles with enhanced photocatalytic performance. RSC Advances 4, 41654 (2014).

87. S.Y. Myong, and K.S. Lim: Highly stable and textured hydrogenated ZnO thin films. Appl. Phys. Lett. 82, 3026 (2003).

88. P. Yang, X. Xiao, Y. Li, Y. Ding, P. Qiang, X. Tan, W. Mai, Z. Lin, W. Wu, T. Li, H. Jin, P. Liu, J. Zhou, C.P. Wong, and Z.L. Wang: Hydrogenated $\mathrm{ZnO}$ core-shell nanocables for flexible supercapacitors and self-powered systems. ACS Nano 7, 2617 (2013).

89. M. Yu, H. Sun, X. Sun, F. Lu, G. Wang, T. Hu, H. Qiu, and J. Lian: Hierarchical al-doped and hydrogenated $\mathrm{ZnO}$ nanowire@ $\mathrm{MnO}_{2}$ ultra-thin nanosheet core/shell arrays for high-performance supercapacitor electrode. Int. J. Electrochem. Sci. 8, 2313 (2013).

90. M.-D. Kim, J.-E. Oh, S.-G. Kim, and W.C. Yang: Hydrogen passivation effect on the yellow-green emission band and bound exciton in n-ZnO. Solid State Commun. 151, 768 (2011).

91. X. Xue, L. Liu, Z. Wang, and Y. Wu: Room-temperature ferromagnetism in hydrogenated Zn0 nanoparticles. J. Appl. Phys. 115, 033902 (2014).

92. Q. Tang, Y. Li, Z. Zhou, Y. Chen, and Z. Chen: Tuning electronic and magnetic properties of wurtzite $\mathrm{ZnO}$ nanosheets by surface hydrogenation. ACS Appl. Mater. Interfaces 2, 2442 (2010).

93. D. Jiang, W. Wang, Y. Zheng, and L. Zhang: Enhanced photon-to-electron conversion and improved waterresistance of hydrogenated ceria in photocatalytic oxidation at gas-solid interface. Appl. Catal. B: Environ. 191, 86 (2016).

94. Z. Weng, W. Liu, L.-C. Yin, R. Fang, M. Li, E.I. Altman, Q. Fan, F. Li, $\mathrm{H} .-\mathrm{M}$. Cheng, and $\mathrm{H}$. Wang: Metal/oxide interface nanostructures generated by surface segregation for electrocatalysis. Nano Lett. 15, 7704 (2015).

95. J. Wei, H. Ji, W. Guo, A.H. Nevidomskyy, and D. Natelson: Hydrogen stabilization of metallic vanadium dioxide in single-crystal nanobeams. Nat. Nanotech. 7, 357 (2012).

96. A.M. Chippindale, P.G. Dickens, and A.V. Powell: Synthesis, characterization, and inelastic neutron scattering study of hydrogen insertion compounds of $\mathrm{VO}_{2}$ (rutile). J. Solid State Chem. 93, 526 (1991).

97. V. Andreev, V. Kapralova, and V. Klimov: Effect of hydrogenation on the metal-semiconductor phase transition in vanadium dioxide thin films. Phys. Solid State 49, 2318 (2007).

98. C. Wu, F. Feng, J. Feng, J. Dai, L. Peng, J. Zhao, J. Yang, C. Si, Z. Wu, and $Y$. Xie: Hydrogen-incorporation stabilization of metallic $\mathrm{VO}_{2}(\mathrm{R})$ phase to room temperature, displaying promising low-temperature thermoelectric effect. J. Am. Chem. Soc. 133, 13798 (2011).

99. G. Wang, Y. Ling, H. Wang, X. Yang, C. Wang, J.Z. Zhang, and Y. Li: Hydrogen-treated $\mathrm{WO}_{3}$ nanoflakes show enhanced photostability. Energy Environ. Sci. 5, 6180 (2012).

100.Y.H. Li, P.F. Liu, L.F. Pan, H.F. Wang, Z.Z. Yang, L.R. Zheng, P. Hu, H. J. Zhao, L. Gu, and H.G. Yang: Local atomic structure modulations activate metal oxide as electrocatalyst for hydrogen evolution in acidic water. Nat. Commun. 6, 8064 (2015).

101.M. Vasilopoulou, I. Kostis, A.M. Douvas, D.G. Georgiadou, A. Soultati, G. Papadimitropoulos, N.A. Stathopoulos, S.S. Savaidis, P. Argitis, and D. Davazoglou: Vapor-deposited hydrogenated and oxygen-deficient molybdenum oxide thin films for application in organic optoelectronics. Surf. Coat. Tech. 230, 202 (2013)

102.J. Hou, H. Cheng, C. Yang, O. Takeda, and H. Zhu: Hierarchical carbon quantum dots/hydrogenated- $\gamma$-TaON heterojunctions for broad spectrum photocatalytic performance. Nano Energy 18, 143 (2015).

103.M. He, Z. Wang, X. Yan, L. Tian, G. Liu, and X. Chen: Hydrogenation effects on the lithium ion battery performance of $\mathrm{TiOF}_{2}$. J. Power Sources 306, 309 (2016)

104.X. Yan, L. Tian, J. Murowchick, and X. Chen: Partially amorphized $\mathrm{MnMoO}_{4}$ for highly efficient energy storage and the hydrogen evolution reaction. J. Mater. Chem. A 4, 3683 (2016).

105.S.X. Weng, and X. Chen: A hybrid electrolyzer splits water at $0.8 \mathrm{~V}$ at room temperature. Nano Energy 19, 138 (2016). 
106.X. Yan, L. Tian, and X. Chen: Crystalline/amorphous Ni/NiO core/shell nanosheets as highly active electrocatalysts for hydrogen evolution reaction. J. Power Sources 300, 336 (2015).

107.X. Yan, L. Tian, M. He, and X. Chen: Three-dimensional crystalline/amorphous $\mathrm{Co} / \mathrm{CO}_{3} \mathrm{O}_{4}$ core/shell nanosheets as efficient electrocatalysts for the hydrogen evolution reaction. Nano Lett. 15, 6015 (2015).

108.X. Yan, K. Li, L. Lyu, F. Song, J. He, D. Niu, L. Liu, X. Hu, and X. Chen: From water oxidation to reduction: transformation from $\mathrm{Ni}_{x} \mathrm{CO}_{3-x} \mathrm{O}_{4}$ nanowires to $\mathrm{NiCo} / \mathrm{NiCoO}_{x}$ heterostructures. ACS Appl. Mater. Interfaces 8, 3208 (2016).

109. L. Tian, X. Yan, and X. Chen: Electrochemical activity of iron phosphide nanoparticles in hydrogen evolution reaction. ACS Catalysis 6, 5441 (2016).

110.X. Yan, L. Tian, K. Li, S. Atkins, H. Zhao, J. Murowchick, L. Liu, and $X$. Chen: $\mathrm{FeNi}_{3} / \mathrm{NiFO}_{x}$ nanohybrids as highly efficient bifunctional electrocatalysts for overall water splitting. Adv. Mater. Interfaces. DOI: 10.1002/ admi.201600368. 